\title{
Investigando os rumos da disciplina escolar Ciências no Colégio Pedro II (1960-1970)*
}

\author{
A research about the history of the General Sciences as a school \\ subject in the Colégio Pedro II (1960-1970)
}

Marcia Serra Ferreira**

\section{Resumo}

Este artigo analisa mecanismos de estabilidade e mudança curriculares produzidos no Colégio Pedro II que influenciaram os rumos da disciplina escolar Ciências no $2^{\circ}$ segmento do Ensino Fundamental, durante os anos 1960-1970. Investigando fontes orais e escritas, afirmo que aspectos institucionais puderam contribuir para que esta sofresse influências do movimento de renovação do ensino de Ciências ocorrido no período. Tais aspectos dizem respeito ao baixo status da disciplina escolar, que possuía um caráter mais generalista, era preterida pelo catedrático e não possuía espaço físico próprio. Essas características viabilizaram mudanças em uma instituição com arraigadas tradições e com as decisões centralizadas nos catedráticos. Tais mudanças, no entanto, articularam as inovações com conteúdos e práticas do passado, inventando uma tradição que pôde agregar o tradicional/antigo com o moderno/renovado e manter o prestígio da disciplina escolar tanto internamente quanto no nível externo.

Palavras-Chave: Currículo; Disciplina Escolar Ciências;

História das Disciplinas Escolares

\section{Abstract}

This paper analyses both the stability and the curriculum changing mechanisms produced in the Colégio Pedro II, which have influenced the course of Science as a school subject in upper elementary school during the 1960-1970'. Based on written and oral sources, the researcher states that institutional aspects had contributed to the fact that the influences from the Science Education innovation movement could be processed in the school subject. The institutional aspects were related to the school subject low status due to the fact that it had a general characteristic, it was less preferred by the head of

Este trabalho foi originalmente apresentado sob o título $A$ disciplina escolar Ciências no Colégio Pedro II: entre as iniciativas inovadoras e a estabilidade curricular, na $28^{\mathrm{a}}$ Reunião Anual da Associação Nacional de Pós-Graduação e Pesquisa em Educação (ANPEd), ocorrida em outubro de 2005 na cidade de Caxambu/MG.

** Professora Dra . do curso de Licenciatura em Ciências Biológicas e do Programa de PósGraduação em Educação da UFRJ. Coordenadora do Núcleo de Estudos de Currículo da Faculdade de Educação da UFRJ (Rio de Janeiro/Brasil). mserra@ufrj.br. 
department and it had not a specific physical space for the lessons. Those characteristics allowed room for changes in a long-term traditional institution in which curriculum decisions used to be centralized on the heads of departments themselves. Such curriculum changes had articulated innovations to teaching contents and practices from the past, and have invented a new tradition that could join the traditional/old to the modern/new. Through this process it was possible to maintain the school subject prestige both internally and in a broader external level.

Keywords: Curriculum; Science as a School Subject; History of School Subjects

\section{INTRODUZINDO A QUESTÃO}

Este artigo tem como objetivo analisar os mecanismos de estabilidade e de mudança curriculares produzidos em uma instituição escolar específica - o Colégio Pedro II -, que influenciaram os rumos da disciplina escolar Ciências ministrada no segundo segmento do Ensino Fundamental, durante as décadas de 1960 e 1970. ${ }^{1}$ Tomando como particular referência o movimento de renovação do ensino de Ciências que ocorria no Brasil e no mundo no mesmo período, busco compreender como as especificidades desse estabelecimento de ensino secundário uma instituição em busca de seu antigo prestígio imperial e com uma forte tradição junto ao ensino das humanidades - puderam participar da construção sócio-histórica da referida disciplina escolar. Para tanto, apóiome nos trabalhos de Ivor Goodson (1995, p. 120), percebendo as disciplinas escolares como "amálgamas mutáveis de subgrupos e tradições" que, em busca de status, recursos e território, tanto entram em disputas quanto se apropriam de determinados padrões de professores, estudantes, temáticas e atividades de ensino, os quais foram socialmente produzidos e legitimados pelos sistemas educacionais. Tais padrões possuem "valor como moeda no 'mercado da identidade social”' (Goodson, 1997, p. 27), e a apropriação destes visa à construção de retóricas mais adequadas para que as comunidades disciplinares obtenham apoio ideológico e recursos materiais dos grupos externos.

A história da disciplina escolar Ciências no Colégio Pedro II foi investigada por meio de documentos e de depoimentos de antigos

1 Ele é parte de uma pesquisa mais ampla que investigou a história da disciplina escolar Ciências, de 1960 a 1980, no Colégio Pedro II, na cidade do Rio de Janeiro (Ferreira, 2005). 
professores da instituição. Minha opção pelo uso de fontes diversificadas teve como objetivo, em primeiro lugar, ampliar as possibilidades de investigação das várias instâncias de reconstrução do currículo escolar. De acordo com Antonio Flavio Moreira (1994), esse uso combinado de materiais escritos e orais como fontes em estudos históricos no campo do Currículo pode nos alertar para os perigos tanto das explicações que desconsideram a força das limitações estruturais como daquelas que secundarizam as ações humanas. Essa opção deveu-se, em segundo lugar, às dificuldades encontradas no levantamento de materiais especificamente curriculares. Dominique Julia (2001, p. 16), ao falar da realidade francesa, afirma que esses materiais têm sido historicamente descartados nas instituições escolares, já que "regularmente, como se diz, é preciso 'arranjar espaço' e os documentos não são nem mesmo transferidos para depósitos de arquivos que deveriam legalmente recebê-los". No caso específico do Colégio Pedro II, particularmente no período investigado, existe pouquíssimos registros de ementas, programas, livros didáticos ou atas de reuniões. Assim, a inclusão dos depoimentos me permitiu não apenas o acesso a uma memória oral que não se encontrava arquivada, mas também a busca por eventuais materiais escritos guardados em arquivos pessoais dos profissionais entrevistados.

O Colégio Pedro II - fundado em 1837 - foi o primeiro estabelecimento oficial de instrução secundária do país. Após um passado imperial de grande prestígio, a instituição buscou sobreviver à instauração do regime republicano e passou por uma série de transformações - tanto de ordem pedagógica quanto políticas e sociais mais amplas -, sempre buscando reinventar formas de se colocar novamente em destaque no contexto educacional do país. Particularmente nos anos 1960-1970, o colégio perdeu de vez a posição de instituição padrão, enfrentando um novo momento de crise, com um número reduzido de estudantes e novas ameaças de transferência para o âmbito estadual. No que se refere à disciplina escolar Ciências, uma avaliação superficial da questão poderia me indicar que essa instituição - imersa em seu currículo predominantemente humanista e em seus problemas administrativos e políticos - teria passado incólume pelo movimento de renovação desse ensino. Além disso, a atuação dos professores catedráticos, que centralizavam as decisões administrativas e pedagógicas do colégio, mas - particularmente no que se refere aos catedráticos de História Natural/Biologia - não estavam diretamente envolvidos com o referido movimento no país, certamente contribuía para estabilizar os currículos em curso na instituição. 
Nos anos 1960, entretanto, o Colégio Pedro II contava com pelo menos dois importantes participantes do movimento de renovação do ensino de Ciências em seu próprio quadro docente: o professor Ayrton Gonçalves da Silva, fundador dos Centros de Ciências no país e primeiro presidente do Centro de Ciências do Estado da Guanabara - CECIGUA -; e a professora Guiomar Gomes de Carvalho, sua parceira tanto no referido Centro de Ciências quanto em vários outros projetos, e que em 1970/71 obteve licença remunerada no Colégio Pedro II para participar de um curso nos Estados Unidos com a equipe do Biological Sciences Curriculum Studies, uma organização que protagonizava o movimento de renovação do ensino de Biologia norte-americano e nos demais países sob sua influência política e econômica.

A presença de tais professores na instituição me permitiu desconfiar das minhas primeiras impressões sobre a disciplina escolar Ciências, buscando entendê-las para além das aparentes e óbvias semelhanças encontradas nos poucos documentos escritos disponíveis para pesquisa. Nesse contexto, a utilização dos depoimentos como fontes de estudo certamente ampliou as possibilidades de compreensão das dinâmicas envolvidas nas decisões e nas ações curriculares, explicitando particularidades e diferenças nem sempre perceptíveis nos "frios" registros em folhas de papel.

Assim, tomando por base a análise tanto dos documentos escritos quanto das fontes orais, afirmo que, nos anos 1960, a disciplina escolar Ciências ministrada no Colégio Pedro II sofreu reais influências do movimento de renovação, o que se expressa tanto nos critérios de seleção e de organização dos conteúdos de ensino quanto na defesa de uma metodologia de caráter experimental. No primeiro caso, os livros didáticos produzidos por docentes da instituição - os professores Waldemiro Potsch, Ayrton Gonçalves da Silva e Carlos Potsch - e utilizados no período ${ }^{2}$ me possibilitaram entender como as influências da experiência adquirida pelo segundo autor penetraram no colégio e favoreceram um ensino com objetivos mais utilitários. No segundo caso, os indícios fornecidos por essa coleção de livros didáticos, assim como os vários depoimentos,

2 Refiro-me aos livros de Potsch, Silva e Potsch, que são: Iniciação à Ciência (1ª $2^{\circledR}$ séries), Ciências Físicas e Biológicas - O corpo humano e a saúde ( $3^{a}$ série) e Ciências Físicas e Biológicas - Matéria e energia. Animais e Plantas ( $4^{a}$ série), publicados pela primeira vez na década de 1960. 
convergiram ao reconhecer que as tentativas de incorporação das inovaçoes passaram em grande parte pelas questões de ordem metodológica.

O estudo realizado igualmente me permitiu compreender como determinados aspectos institucionais puderam contribuir para essa entrada de influências do movimento de renovação na disciplina escolar Ciências ministrada no Colégio Pedro II. Tais aspectos dizem respeito ao baixo status da referida disciplina escolar quando comparada aos próprios cursos de Física, Química e História Natural ministrados no Ensino Médio. Afinal, a disciplina escolar Ciências possuía um caráter mais generalista e menos específico, sendo preterida pelo catedrático - que geralmente a entregava aos docentes mais novos no colégio -, e não mais contava com espaço físico próprio. Como veremos, esse conjunto de características viabilizou espaços de mudanças em uma instituição com arraigadas tradições e com as decisões curriculares fortemente centralizadas nas mãos dos professores catedráticos.

As duas seções que se seguem buscam explicitar as condições e os mecanismos que viabilizaram as influências inovadoras na disciplina escolar investigada. Em um primeiro momento, analiso o movimento mais amplo de renovação do ensino de Ciências que ocorria no Brasil e no mundo; em um segundo momento, focalizo os mecanismos que se constituíram institucionalmente e permitiram a apropriação de elementos desse movimento durante os anos 1960 e 1970.

\section{Analisando o movimento de renovação do ensino de Ciências}

O movimento de renovação do ensino de Ciências chega ao Brasil em meio a uma série de experiências inovadoras que atingem o ensino secundário. ${ }^{3}$ Segundo Maria Luisa Ribeiro e Miriam Warde (1995), tais experiências surgem de uma insatisfação com a educação dualista ministrada em nosso país - que destinava um ensino propedêutico às elites versus um ensino profissional para o restante da população que crescentemente chegava à escola - e retomam os intensos debates educacionais dos anos 1930, os quais foram interrompidos com a instauração do Estado Novo. Nesse novo momento, para essas autoras,

3 Uma dessas experiências foi a legislação que permitiu a introdução de Classes Experimentais em escolas secundárias do país. Sobre o projeto de Classes Experimentais desenvolvido no Colégio de Aplicação da Universidade Federal do Rio de Janeiro, ver Ferreira et al. (2001). 
A via tomada foi a de abrir a escola para questões mais ligadas à vida (como forma de romper com o academicismo vigente), permitir maior participação do aluno (como forma de superar o verbalismo professoral), buscar maior integração entre as matérias (como forma de ultrapassar a fragmentação do conhecimento) e, em síntese, instalar os métodos ativos (Ribeiro; Warde, 1995, p. 214).

Não é por acaso, portanto, que encontramos no movimento de renovação do ensino de Ciências uma forte opção por métodos ativos de ensino. Segundo Myriam Krasilchik (1995, p. 177), esse movimento ligado às disciplinas escolares em Ciências teve início em nosso país ainda nos anos 1950, com o trabalho desenvolvido na secção de São Paulo do Instituto Brasileiro de Educação, Ciência e Cultura - IBECC -, voltado para "atualizar os conteúdos então ensinados nas escolas secundárias, e tornar o ensino prático". Muitos autores, entretanto, situam nos anos 1960 o surgimento de um movimento de renovação do ensino de Ciências mais amplo. Afinal, foi somente após o lançamento do satélite artificial soviético Sputnik 1, em 1957, que os Estados Unidos e a Inglaterra começaram a organizar centros e comitês nacionais para a produção de materiais didáticos e a financiar projetos em países da América Latina (Barra; Lorenz, 1986). Nesse momento, as desvantagens tecnológicas foram compreendidas, em parte, como decorrentes de uma educação deficitária em Ciências (Chassot, 2004). Dessa explicação resultaram crescentes investimentos no ensino de Ciências, os quais atingiram tanto os dois países anteriormente citados quanto diversos outros membros do bloco capitalista.

Nos Estados Unidos e na Inglaterra, a associação de cientistas, educadores e professores em centros e comitês resultou, entre outros materiais, na produção de coleções de livros didáticos para o atual Ensino Médio. ${ }^{4}$ Nos anos 1960, essas coleções foram traduzidas e adaptadas em nosso país pelo IBECC, sendo publicadas por meio de um convênio com a Universidade de Brasília. Esse esforço foi viabilizado, em primeiro lugar, pela Fundação Ford - que financiou o trabalho do instituto - e, em segundo lugar, pela United States Agency for International Development - USAID - que,

4 Refiro-me aos materiais produzidos no âmbito do projeto inglês Nuffield e aos materiais norte-americanos que ficaram conhecidos por suas iniciais, tais como o BSCS (Biological Sciences Curriculum Study), o PSSC (Physical Science Study Committee), o CBA (Chemical Bond Approach) e o CHEMS (Chemical Educational Material Study). 
de acordo com Vilma Barra e Karl Lorenz (1986), se comprometeu a financiar os primeiros 36.000 exemplares publicados.

No caso específico da disciplina escolar Ciências, nesse mesmo período o IBECC produziu um material brasileiro - o projeto Iniciação à Ciência - que, segundo Myriam Krasilchik (1995, p. 186), divergia dos materiais estrangeiros ao inserir as atividades práticas no próprio corpo do texto, "fazendo parte de um conjunto que tornava obrigatória a execução das experiências". De acordo com essa autora, originalmente o material constava de uma introdução - na qual os estudantes tinham a oportunidade de vivenciar algumas etapas do método científico - e de unidades curriculares a serem organizadas pelos próprios professores. Posteriormente, em função das dificuldades docentes na organização dos conteúdos de ensino, bem como dos problemas advindos da comercialização do referido material em fascículos, o Iniciação à Ciência foi transformado em livro didático. Ainda segundo Krasilchik (1995), em ambos os formatos do projeto a importância conferida à experimentação fez com que seus idealizadores optassem pelo uso de materiais simples, que pudessem ser facilmente encontrados pelos diversos professores.

O conjunto dos autores anteriormente citados - Vilma Barra e Karl Lorenz (1986), Myriam Krasilchik (1995) e Attico Chassot (2004) claramente percebe o contexto internacional pós-Sputnik como o grande influenciador do movimento de renovação do ensino de Ciências brasileiro. Seus trabalhos, entretanto, pouco analisam o referido movimento no contexto das renovações educacionais que, simultaneamente, ocorriam no país. No presente estudo, embora obviamente reconheça a importância das análises desses autores, apóio-me em Ivor Goodson (1996 e 1997) ao compreender que as influências internacionais no movimento de renovação do ensino de Ciências puderam penetrar mais fortemente no contexto brasileiro porque seu ideário possuía afinidades com esse movimento de renovação educacional mais amplo.

Como já anteriormente explicitado, as primeiras medidas educacionais inovadoras ocorridas no Brasil ao final dos anos 1950 foram impulsionadas pelos debates em torno da dualidade de nosso sistema escolar. De acordo com Maria Luisa Ribeiro e Miriam Warde (1995), embora a Lei de Diretrizes e Bases promulgada no ano de $1961^{5}$ tenha conferido uma maior flexibilidade curricular aos diversos graus e ramos de ensino,

5 Brasil. Lei 4.024 de 20 de dezembro de 1961. Fixa as Diretrizes e Bases da Educação Nacional. 
permitindo tanto a transferência de um ramo para outro quanto a correspondência entre eles para o ingresso no ensino superior, não foi capaz de modificar substancialmente o cenário educacional do país. As experiências inovadoras surgiram, portanto, em meio a essa dualidade entre ensino propedêutico versus ensino profissional, tendo se desenvolvido basicamente no ramo secundário do nível Médio e ficando restritas, em grande parte, ao ciclo ginasial. Do mesmo modo, no caso específico do Colégio Pedro II, as experiências inovadoras trazidas pelo movimento de renovação do ensino de Ciências parecem ter atingido preferencialmente a disciplina escolar Ciências, que ocupava a grade do curso ginasial e igualmente reunia as melhores condições institucionais para o surgimento de determinadas mudanças curriculares. É sobre essas condições produzidas na própria instituição escolar que trata a próxima seção.

\section{INVESTIGANDO OS MECANISMOS DE ESTABILIDADE E DE MUDANÇA CURRICULARES}

Como já mencionado no início desse trabalho, a história da disciplina escolar Ciências no Colégio Pedro II foi investigada por meio de depoimentos e de documentos do currículo escrito. Nesse último caso, os livros didáticos produzidos e adotados no período constituíram uma inestimável fonte de estudo, uma vez que, além dos conteúdos de ensino, ainda traziam os programas oficiais da instituição impressos no próprio material. Segundo uma das professoras entrevistadas, esses textos didáticos “já eram muito avançados para a época”, uma vez que - graças à parceria dos professores catedráticos com o professor Ayrton Gonçalves da Silva - a referida coleção explicitamente incorporava determinadas inovações oriundas do movimento de renovação do ensino de Ciências, tais como "problemas e práticas, coisas que tinham muito a ver com a vida das pessoas. Ele também possuía exercícios mais inteligentes” (professora B). Para essa mesma entrevistada, a versão anterior do material dos catedráticos - sem a participação do professor Ayrton - "só tinha os conteúdos descritos" e, nesse sentido, "a proposta de colocar os alunos para resolver problemas e a proposição de experimentos melhoraram muito o livro do professor Waldemiro. Era um livro mais voltado para o ensino renovado de ciências" (professora B).

A influência norte-americana no movimento de renovação do ensino de Ciências brasileiro se explicita no depoimento de um dos professores entrevistados, antigo aluno do Colégio Pedro II nos anos 1950. Falando sobre esse período, ele afirma: 
Como estudante eu tive pouca Ciência, porque naquela época a Ciência era dada na terceira e na quarta séries. Na terceira série eram noções sobre os seres vivos e o corpo humano, [...] um conteúdo, quantitativamente falando, muito pequeno. E na quarta série já era física e química, mas um conteúdo também muito pequeno. A ciência parecia não ser muito importante. $O$ conhecimento científico não era muito priorizado. A partir de 1957, com a formação daquelas escolas americanas, é que nós realmente começamos a ter um contato maior e as escolas começaram a modificar os seus currículos, até na metodologia (professor C).

O depoimento anterior reafirma a característica predominantemente humanista dos currículos secundários no país - o que inclui o Colégio Pedro II - até pelo menos os anos $1960 .^{6}$ Tal aspecto certamente contribuiu para o modo como a instituição lidou com as inovações curriculares propostas para o ensino de Ciências nesse período. Entretanto, sustento que os aspectos de ordem institucional que favoreceram a entrada de influências do movimento de renovação na instituição dizem respeito, em grande parte, ao baixo status da disciplina escolar Ciências quando comparada às disciplinas escolares Física, Química e História Natural/Biologia. Afinal, a referida disciplina escolar possuía um caráter mais generalista e menos específico, sendo preterida pelo catedrático - que geralmente a entregava aos docentes mais novos no colégio - e não mais contava com espaço físico próprio. Tal movimento pôde influenciar os rumos sócio-históricos da disciplina escolar Ciências porque esta não constituía o foco de atenção do Colégio Pedro II e de seus profissionais mais poderosos: os professores catedráticos.

De acordo com Ivor Goodson (1996 e 1997), todo estudo sobre mudanças curriculares deve associar a análise de aspectos internos à constituição das várias disciplinas escolares com contextos externos a elas. Para o autor, um dos mecanismos a produzir estabilidade nos currículos escolares refere-se ao fato de que, na maioria das vezes, as transformações planejadas em um determinado nível não estão em sintonia com as idéias e os interesses produzidos nos outros níveis. Em minha

6 Embora em 1931 a Reforma Francisco Campos tenha aumentado a carga horária das disciplinas escolares em ciências, tal ampliação não foi suficiente para ultrapassar o tempo destinado ao ensino das humanidades. A legislação posterior - a Reforma Gustavo Capanema, promulgada em 1942 - reduziu novamente o tempo das disciplinas escolares em ciências, defendendo um ensino de ciências elementar e não aprofundado. 
investigação, por exemplo, embora o contexto disciplinar criado especialmente a partir dos anos 1960 - impulsionado pelas influências do movimento de renovação norte-americano e pela criação dos Centros de Ciências no país - possa ter favorecido o surgimento de mudanças curriculares na disciplina escolar Ciências em vários estabelecimentos de ensino do país, aspectos referentes ao próprio Colégio Pedro II não necessariamente apontavam nessa mesma direção de mudança.

Isso significa dizer que, embora tenham existido modificações na seleção de conteúdos e nos métodos de ensino da referida disciplina escolar durante o período investigado, tais transformações não foram suficientes para promover uma reforma curricular que atingisse a todos os docentes e que modificasse substancialmente todo o ensino de Ciências no colégio. Tal constatação, no entanto, não constitui um problema para a realização desse estudo, uma vez que, apoiando-me em Goodson (1995), não analiso a disciplina escolar Ciências como um bloco monolítico, mas procuro compreender a existência de um cotidiano conflituoso, que envolvia disputas entre tradições disciplinares anteriores e todo um ideário do movimento de renovação que começava a se delinear no período. Além disso, busco levar em conta a noção de que também estavam em jogo as tradições da própria instituição escolar.

$\mathrm{Na}$ ocasião, um dos importantes elementos a ainda contribuir para a construção das disciplinas escolares no Colégio Pedro II era certamente a existência e a influência dos professores catedráticos. ${ }^{7}$ O prestígio e o poder institucional desses profissionais eram tão grandes que, segundo depoimento de uma das entrevistadas, os demais professores "não tinham acesso direto a eles. Nós conversávamos e tudo, mas eles pareciam deuses" (professora A). Para ela, essa distância “era uma tônica do colégio. Quando os professores passavam, os funcionários ficavam de pé, em posição de soldadinho. Assim também eram os professores em relação aos catedráticos" (professora A).

Apesar de os catedráticos assumirem uma posição profissional que guardava distância tanto dos funcionários quanto dos demais professores do colégio, o depoimento de um funcionário - que ingressou na instituição

7 Embora as cátedras tenham sido extintas com a reforma universitária de 1968, os professores catedráticos anteriormente concursados continuaram atuando até a aposentadoria. 
nos anos 1960 e, posteriormente, foi designado para atuar no gabinete/ laboratório de História Natural/Biologia - permite explicitar as relações hierárquicas que se estabeleciam no período: "Nós tivemos, na época dos catedráticos, muito reconhecimento pelos colegas, pelos professores. Eu aprendi muita coisa aqui com o carinho e o amor que eles tinham pela gente" (funcionário). Segundo ele, esses profissionais:

Eram a mola mestra do Colégio Pedro II. O colégio perdeu o seu poderio com o fim dos catedráticos. [...] Mas vou te dizer, os catedráticos tinham tanto jogo de cintura que até nos militares eles conseguiam se infiltrar e não houve assim tanto abalo (funcionário).

No caso específico da disciplina escolar Ciências, o professor Carlos Potsch - profissional que participava das reuniões da Congregação desde 1954, ano em que prestou concurso para livre docente, ${ }^{8}$ tornando-se catedrático interino em $1955^{\circ}$ e tendo realizado, logo em seguida, concurso para a cátedra de História Natural ${ }^{10}$ - possuía um prestígio adicional, uma vez que era herdeiro de uma tradição familiar, pois seu pai - o professor Waldemiro Potsch - foi o catedrático anterior da seção de História Natural.

Embora os catedráticos conferissem um caráter acadêmico às suas disciplinas escolares, segundo o depoimento de uma das entrevistadas, eles preferencialmente ministravam aulas no curso Científico. Tal preferência se dava, em primeiro lugar, pela faixa etária dos estudantes; em segundo lugar, pela possibilidade de trabalhar com uma disciplina escolar mais específica, que permitisse abordar o assunto de sua especialidade como catedrático: "por exemplo, o professor Carlos Potsch era botânico. Então, ele gostava mais de ensinar a parte ligada a Botânica, e a série que ele pegava era aquela aonde tinha uma abrangência dessa parte de Botânica” (professora A).

Assim, ao assumir as turmas de História Natural/Biologia, o professor Carlos Potsch deixava as aulas da disciplina escolar Ciências

8 Congregação do Colégio Pedro II. Ata de 01 de dezembro de 1954 (Livro 06).

9 Congregação do Colégio Pedro II. Ata de 13 de outubro de 1955 (Livro 06).

10 Embora não tenha obtido informação precisa sobre o início da cátedra do professor Carlos Potsch no Colégio Pedro II, presumo que o concurso ocorreu entre 1956 e 1957, uma vez que a ata da Congregação de 09 de abril de 1956 (Livro 06) trata da banca do referido concurso, e a ata da Congregação de 08 de abril de 1957 (Livro 06) anuncia que a recepção tanto do professor Carlos Potsch quanto do professor Rocha Lima como catedráticos ainda não havia ocorrido. 
sob a responsabilidade dos docentes mais novos na instituição. A contratação desses professores certamente passava por critérios de escolha do próprio catedrático, que acabava por priorizar tanto as relações familiares - uma vez que a família Potsch possuía vários docentes nessa área - quanto as relações profissionais, convidando alguns de seus próprios alunos de uma universidade privada: "porque existiam muitas pessoas que vinham da Santa Úrsula, que ele conhecia o trabalho de perto. Eu mesmo fui aluna do professor Carlos Potsch em Botânica, na Faculdade" (professora A). Apesar de essa forma de seleção do corpo docente constituir um mecanismo de estabilidade curricular, o fato de os novos professores assumirem preferencialmente a disciplina escolar Ciências certamente gerou espaço para determinadas influências do movimento de renovação, uma vez que alguns desses professores eram mais suscetíveis às mudanças e estavam "vindo para a escola com aquela força total, fazendo cursos no Centro de Ciências, aquele também em São Paulo com a Myriam Krasilchik" (professora A).

A atuação dos catedráticos na instituição envolvia tanto as decisões de caráter pedagógico quanto o seu controle administrativo e político. No caso específico da cátedra de História Natural/Biologia, o professor Carlos Potsch parecia assumir uma postura de pouco confronto, o que se expressa tanto em uma quase ausência de suas falas nos registros de reuniões da Congregação ${ }^{11}$ quanto no modo de conduzir as questões pedagógicas. Sobre as decisões curriculares, por exemplo, uma das professoras entrevistadas afirma que, embora o Colégio Pedro II possuísse um programa que "tinha que ser cumprido, [...] nós tínhamos uma flexibilidade na maneira de levar esse conteúdo para os alunos. Ele [o professor Carlos Potsch] nos dava toda a liberdade" (professora A). Do mesmo modo, duas outras entrevistadas destacam a falta de uma orientação mais específica do catedrático. Uma dessas professoras afirma: "Primeiro ele tinha uma confiança muito grande na sua equipe. Então ele dava uma orientação geral e, quem tinha dúvidas, recorria a ele. Ele estava sempre pronto a nos ajudar, a esclarecer..." (professora D).

Entretanto, essa postura de pouco confronto assumida pelo professor Carlos Potsch não significava uma ausência de controle das decisões pedagógicas da seção/departamento de História Natural/

11 Refiro-me aos livros de atas de números 06 e 07, que reúnem os registros das reuniões da Congregação do Colégio Pedro II ocorridas entre os anos de 1954 e 1975. 
Biologia. Segundo uma das professoras entrevistadas, "nada era resolvido aqui, dentro da área de Biologia ou de ciências em geral, eu falo em ciências em geral, sem que passasse pelas mãos dele" (professora A). Todas as iniciativas, desde o desejo de participar de um curso de atualização até a idéia de realizar um novo projeto, passavam pela aprovação do catedrático. Então, para essa entrevistada, "o professor realmente tinha uma autonomia, desde que participasse ao chefe de Departamento o que estava sendo feito. Muitas vezes, dependendo da pessoa, ele liberava" (professora A).

O prestígio institucional dos professores catedráticos também estava relacionado ao espaço físico destinado a cada uma das disciplinas escolares. No caso específico das disciplinas escolares em ciências, o Colégio Pedro II sempre possuiu orientações legais acerca desses espaços específicos os gabinetes - destinados ao ensino das Ciências Físicas e Naturais. Tais gabinetes obviamente ficavam sob a responsabilidade direta dos catedráticos que, em muitos casos, os tomavam como salas particulares, dificultando as possibilidades de utilização didática desses locais pelos outros professores. Segundo uma das entrevistadas, esses eram espaços totalmente reservados e, "para você entrar em um determinado gabinete, era um ritual. O de Biologia sempre foi um pouco mais aberto. O professor Carlos Potsch, também porque não podia estar presente, ele liberava. Depois mudou. Havia uma época em que ele dominava" (professora A).

Como evidenciado no depoimento anterior, o gabinete ocupado pelo professor Carlos Potsch destinava-se à disciplina História Natural/Biologia. Nos anos 1960-1970, portanto, não havia um ambiente específico para as atividades da disciplina escolar Ciências; assim como o seu ensino estava sobre a responsabilidade dos professores de História Natural, suas aulas práticas ocupavam os tempos livres desse mesmo gabinete. Tal aspecto certamente reforçava o baixo status da disciplina escolar Ciências frente aos demais estudos científicos, uma vez que, além de constituir uma disciplina escolar pouco específica e, portanto, de menor interesse para o catedrático de História Natural, não possuía espaço físico próprio.

Essa afirmação é corroborada por uma das professoras entrevistadas, para quem o curso ginasial "tinha pouco acesso ao laboratório" (professora A). Entretanto, ela também coloca que essa mesma realidade não impedia a realização de determinadas atividades práticas que, em certos casos, eram executadas no próprio espaço físico da sala de aula. Segundo a entrevistada,

algumas vezes, em alguns conteúdos, nós desenvolvíamos uma demonstração da parte prática e, muitas vezes, nós dividíamos a 
turma em grupos. Cada grupo trazia um material, era uma confusão muito grande porque você não levava o aluno ao laboratório. Você fazia isso dentro da sala de aula (professora A).

O único funcionário entrevistado nesse estudo - que atuava ao lado do catedrático no gabinete de História Natural/Biologia - parece discordar do depoimento da professora, ao colocar que esse espaço era efetivamente utilizado para a realização de experimentos também com os estudantes do curso ginasial. Tal afirmação é reforçada pelo fato de que, além de o professor Carlos Potsch atuar preferencialmente no curso científico, ele igualmente não costumava ministrar aulas práticas: "ele era mais de sala de aula. Laboratório eram mais os outros professores" (funcionário). Na verdade, os catedráticos "preparavam os seus comandados, e todos aqueles que vinham para cá para o colégio faziam uma triagem com eles. Eles é que davam as coordenadas. Os novatos iam” (funcionário).

As características da disciplina escolar Ciências anteriormente destacadas - o seu caráter generalista, a sua responsabilidade nas mãos dos novos professores da instituição e a ausência de um espaço físico próprio - contribuíram para o favorecimento de certas influências do movimento de renovação do ensino de Ciências que ocorria no Brasil e no mundo. Tomando como particular referência esse movimento, minhas conclusões não indicam mudança e estabilidade como fenômenos isolados, mas caminham no sentido de compreender as próprias mudanças a colaborar para a estabilidade curricular da disciplina escolar Ciências.

\section{Buscando CONCLUIR}

A concepção de inovação utilizada no presente trabalho parece diferir daquela empregada em muitos dos estudos já existentes tanto no ensino de Ciências quanto no próprio campo da Educação. Tomando como referência especialmente os escritos de Ivor Goodson (1995, 1996 e 1997), busquei compreender a disciplina escolar Ciências no Colégio Pedro II em meio a movimentos que ora se aproximam e ora se afastam das iniciativas inovadoras, e não como uma "entidade monolítica" - para usar uma expressão de Goodson (1995, p. 120) - que somente pode ser percebida de forma dicotômica, ou seja, como tradicional/antiga ou como moderna/renovada. Para tanto, investiguei os mecanismos gerados na própria instituição que influenciaram a estabilidade e a mudança da 
disciplina escolar Ciências - tais como a existência das cátedras e a seleção de docentes -, entendendo que ambos os processos não ocorrem de modo excludente mas que, ao contrário, são exatamente as mudanças trazidas pela incorporação de certas inovações que colaboram para a estabilidade curricular das diferentes disciplinas escolares.

De acordo com Goodson (1997, p. 30), uma melhor compreensão da estabilidade e da mudança nos currículos escolares passa, necessariamente, pela constituição de modelos analíticos que busquem “examinar os assuntos internos 'em paralelo' com as relações externas, como um modo de desenvolver pontos de vista sobre a mudança organizacional e sobre as mudanças em categorias institucionais mais amplas". Afinal, para o autor, a estabilidade que usualmente observamos nas diferentes disciplinas escolares pode ser muito menos uma ausência de transformações, e sim o resultado de uma série de conflitos tanto no interior das comunidades disciplinares quanto destas com os vários grupos externos.

No Colégio Pedro II, por exemplo, evidencio que a disciplina escolar Ciências não sofreu uma grande reforma no período investigado; apesar disso, ao desconfiar da aparente estabilidade de seus currículos, pude perceber mudanças que foram sendo produzidas até mesmo para garantir a estabilidade disciplinar, tais como a incorporação de certas inovações trazidas pelos profissionais da instituição que participavam ativamente do movimento de renovação do ensino de Ciências. Nos anos 1960-1970, isso ocorreu especialmente por meio da associação dos catedráticos de História Natural/Biologia - os professores Waldemiro Potsch e Carlos Potsch - com o professor Ayrton Gonçalves da Silva, com a finalidade de incorporar a retórica inovadora nos livros didáticos do colégio.

Ivor Goodson (1997) possibilita uma melhor compreensão dessa questão ao destacar que é pouco provável que mudanças dessa natureza - isto é, ocorridas em apenas uma disciplina escolar, em uma instituição específica -, sem um significativo apoio da própria instituição e/ou dos grupos externos mais amplos, venham a produzir efeitos que permaneçam por longo tempo. Segundo o autor, é justamente o estabelecimento de transformações de caráter mais amplo, com um conjunto de práticas a elas associadas, que "acarreta as sementes de novos padrões de tradição e inércia", o que significa entender que, "em suma, a mudança fundamental exige a 'invenção de (novas) tradições”" (Goodson, 1997, p. 31). 
Apesar disso, o presente estudo me permite afirmar que esse mesmo movimento dos referidos catedráticos da instituição viabilizou uma série de mudanças que, ao serem incorporadas nos currículos da disciplina escolar Ciências, possibilitaram a constituição e a manutenção do prestígio institucional de uma disciplina escolar que não necessariamente gozava de tal atributo no passado. $\mathrm{Na}$ verdade, se, por um lado, a incorporação de conteúdos e práticas curriculares que se encontravam explicitamente relacionadas ao movimento de renovação do ensino de Ciências permitiu a atualização da retórica da referida disciplina escolar; por outro, o estabelecimento desses novos conteúdos e práticas, mesmo que executados pelos docentes mais novos no Departamento de Ciências/Biologia, também exigiu a aprovação dos profissionais de maior prestígio no colégio, quais sejam, os professores catedráticos. Nesse sentido, tais conteúdos e práticas curriculares tiveram que se adequar ao que já era tradicionalmente realizado na disciplina escolar, realizando uma série de mudanças que, antes de reformá-la completamente, puderam efetivamente auxiliar na sua estabilidade.

Remetendo-me novamente aos escritos de Goodson (1995), entendo que todo esse processo de incorporação de determinadas inovações na disciplina escolar Ciências ministrada no Colégio Pedro II exigiu uma espécie de "invenção de tradição". Utilizando Eric Hobsbawm (2002) como referência, Goodson (1995, p. 27) defende que "a elaboração de currículo pode ser considerada um processo pelo qual se inventa tradição", e que o currículo escrito é um exemplo perfeito dessa invenção, uma vez que o termo "tradição inventada" refere-se a:

Um conjunto de práticas, normalmente reguladas por regras tácita ou abertamente aceitas; tais práticas, de natureza ritual ou simbólica, visam inculcar certos valores e normas de comportamento através da repetição, o que implica, automaticamente, uma continuidade em relação ao passado. Aliás, sempre que possível, tenta-se estabelecer continuidade com um passado histórico apropriado (Hobsbawm, 2002, p. 9).

No sentido proposto por Goodson (1995), como os currículos escolares são espaços conflituosos tanto de produção quanto de reprodução desses "valores e normas de comportamento" citados por Hobsbawm (2002, p. 9), nos quais os objetivos diretamente relacionados ao ensino encontram-se submetidos à um conjunto de finalidades de ordem política 
e social mais ampla, eles acabam por inventar tradições que precisam estar ancoradas em "um passado histórico apropriado". No caso específico da disciplina escolar Ciências aqui investigada, as mudanças propostas nos anos 1960-1970, embora executadas somente por uma parcela de profissionais do Colégio Pedro II - os seus docentes mais novos -, tornaram-se parte de uma retórica tradicionalmente adotada pelos catedráticos de História Natural/Biologia. Tal retórica inovadora pôde ser disseminada no "mercado da identidade social" (Goodson, 1997, p. 27), especialmente por meio dos livros didáticos produzidos no período, que atingiram não apenas a referida instituição, como também, segundo o depoimento de um dos entrevistados, diversas outras partes do país. Esses materiais didáticos, no entanto, trouxeram as inovações articuladas com os conteúdos e práticas do passado, inventando uma tradição que pôde agregar o tradicional/antigo com o moderno/renovado e, nesse sentido, manter o prestígio da disciplina escolar Ciências tanto internamente - em uma instituição tradicional e ainda tão ligada ao ensino das humanidades como o Colégio Pedro II - quanto no nível externo mais amplo.

\section{Referências Bibliográficas}

BARRA, V. M.; LORENZ, K. M. Produção de materiais didáticos de Ciências no Brasil, período: 1950 a 1980. Ciência e Cultura, São Paulo, v. 38, n. 12, p. 19701983, 1986.

CHASSOT, A. Ensino de Ciências no começo da segunda metade do século da tecnologia. In: LOPES, A. C.; MACEDO, E. (Org.). Curriculo de Ciências em debate. Campinas: Papirus, 2004. p. 13-44.

FERREIRA, M. S.; GOMES, M. M.; LOPES, A. C. Trajetória histórica da disciplina escolar Ciências no Colégio de Aplicação da UFRJ (1949-1968). Proposições, Campinas, p. 9-26, 2001.

FERREIRA, M. S. A bistória da disciplina escolar Ciências no Colégio Pedro II (19601980). 2005. 212p. Tese (Doutorado em Educação) - Faculdade de Educação, Universidade Federal do Rio de Janeiro, Rio de Janeiro, 2005.

GOODSON, I. F. Currículo: teoria e história. Petrópolis: Vozes, 1995.

GOODSON, I. F.; MARSH, C. J. Studying School Subjects - a Guide. London: Falmer Press, 1996.

GOODSON, I. F. A construção social do currículo. Lisboa: Educa, 1997.

HOBSBAWM, E. Introdução: a invenção das tradições. In: HOBSBAWM, E.; RANGER, T. (Org.). A invenção das tradições. 3. ed. Rio de Janeiro: Paz e Terra, 2002. p. 9-23. 
JULIA, D. A cultura escolar como objeto histórico. Revista Brasileira de História da Educação, n. 1, Campinas, p. 9-43, 2001.

KRASILCHIK, M. Inovação no ensino das Ciências. In: GARCIA, W. E. (Coord.). Inovação educacional no Brasil: problemas e perspectivas. 3. ed. São Paulo: Cortez e Autores Associados, 1995. p. 177-194.

MOREIRA, A. F. B. História do currículo: examinando contribuições e alternativas. In: ENCONTRO NACIONAL DE DIDÁTICA E PRÁTICA DE ENSINO, 7, 1994, Goiânia. Anais... Conferências, Mesas Redondas e Simpósios. UFMT, 1994. RIBEIRO, M. L. S.; WARDE, M. J. O contexto histórico da inovação educacional no Brasil. In: GARCIA, W. E. (Coord.). Inovação educacional no Brasil: problemas e perspectivas. 3. ed. São Paulo: Cortez e Autores Associados, 1995. p. 211-222.

Recebido em: 21/01/07 Aprovado em: 22/03/07 